\title{
Sampling for Genetically Modified Organisms Content Analysisin Agricultural Products: From Analytical Sample to Test Portion
}

\author{
Jing Xu ${ }^{\dagger}$, Jiang Zheng ${ }^{\dagger}$, Lu Gao, Jijuan Cao* \\ Inspection and Quarantine Technology Centre of China Customs, Dalian, China
}

\section{Email address:}

cjj0909@163.com (Jijuan Cao)

${ }^{*}$ Corresponding author

${ }^{\dagger}$ Jing Xu and Jiang Zheng are co-first authors.

\section{To cite this article:}

Jing Xu, Jiang Zheng, Lu Gao, Jijuan Cao. Sampling for Genetically Modified Organisms Content Analysisin Agricultural Products: From Analytical Sample to Test Portion. International Journal of Nutrition and Food Sciences. Vol. 8, No. 1, 2019, pp. 23-29. doi: $10.11648 /$ j.ijnfs.20190801.13

Received: March 12, 2019; Accepted: April 27, 2019; Published: May 23, 2019

\begin{abstract}
Objective: At present, Sampling standards and regulations for genetically modified organisms (GMO) are commonly based on theoretical calculations or computer simulations, and there is a lack of field data to validate these simulations. In view of this situation, we sampled agricultural products for GMO content analysis, and investigated the influence of various factors on the accuracy of the results. We have prepared a three-part series and in this part focused on the process from analytical sample to test portions. Method: Using non-transgenic maize as matrix, 12 lines of transgenic maize were used to produce standard analytical samples. After systematic sampling, the GMO contents of these samples were randomly tested, and their single relative standard deviations (RSD) were calculated as a measure of total RSD (single analysis) per sample. Results: By comparing the RSDs of various sampling methods, it was found that the results of 12 strains were basically consistent, and the data of MON810 were listed as a representative. The parameters affecting the standard deviation included the content $\left(a_{A S}\right)$, particle size $\left(d_{A S}\right)$, test portion mass $\left(M_{T P}\right)$ and the number of increments $\left(n_{I T}\right)$. Total analytical RSD could be reduced by decreasing particle size, and increasing test portion mass or the number of increments. Based on current laboratory testing conditions and current used kits, for high content analytical sample $(>0.01 \%)$, more than 2 duplicate test portions with at least -100 mesh particle size and 200mg mass were recommended. Conclusion: Based on the results, the recommended values of particle size, test portion mass and the number of increments for the process from analytical sample to test portions were given. These factors were independent on species or strains of the product, so the results were suitable to all species and strains, provided that the solid particles could be crushed to required particle size.
\end{abstract}

Keywords: Genetically Modified Organisms (GMOs), Sampling, Agricultural Products

\section{Introduction}

In the past 30 years, the planting area and yield of genetically modified organisms (GMOs) have continuously increased ${ }^{[1]}$, but its impact on human health is still unclear. Some countries believe that genetically modified products (GM products) are harmless, and GMO lines can be planted and processed provided that they are approved by the government. However, many countries are cautious about the effects of GM products, and have adopted strict technical measures for the cultivation, entry and sale of GM products.
These restrictions have led to frequent disputes in the international trade of GM products, thus raising the requirements for GM testing [2-7].

The way in which the sample is collected plays a vital role in the accuracy of the test results. Accurate sampling of agricultural products containing GM ingredients has become an important research topic for scientists and technicians [8], and the European Union (EU) [9-12], ISO [13, 14] and China [15] have formulated regulations for GMO sampling. However, these regulations rely on theoretical calculations and computer simulations, and analysis using actual data is 


\section{lacking.}

Several researches on the GM sampling method have been reported [16-22]. Begg et al [17] found that under the controlled conditions of a single laboratory, the error associated with the real-time PCR assay to be negligible in comparison with sampling error. Brera et al [18] reported the sampling procedures that used 10 increment samples provided the best results, in terms of precision and accuracy. Minkkinen et al [20] found that 42 was the absolute minimum number of increments needed for reliable characterization of all lots. Most researches gave summarized suggestion on the whole sampling method, and there is a lack of detailed data on the separated procedure of GM sampling.

GM products are often sampled in three steps: the lot to laboratory sample, the laboratory sample to analytical sample, and the analytical sample to test portion. We will make a detailed study on the whole process in a three-part series, and in this part we have focused on the process of the analytical sample to test portion. Field data has been collected by sampling agricultural products for GMO content analysis, and the influence of various factors on the accuracy of the results have been analyzed; finally we gave the recommended values of particle size, test portion mass and the number of increments for the process from analytical sample to test portions, providing a reference for future studies.

\section{Materials and Methods}

\subsection{Testing Materials}

GM reference materials T25, MON88017 and MON87640 were purchased from American Oil Chemists' Society, USA.

GM reference materials TC1507, NK603, MON863, MON810, GA21, BT176, BT11, ES3272 and MIR604 were purchased from Sigma Aldrich (China).

\subsection{Instruments}

DNA extraction kit for GMO detection Ver2.0 (No. D9093) was purchased from Takara Biomedical Technology (Beijing) Co., Ltd., China.

Real time PCR analyzer (ABI7500) was purchased from Thermo Fisher Scientific Applied Biosystems, USA.

\subsection{Preparation of Standard Analytical Samples}

After lyophilization, transgenic and non-transgenic maize grains were crushed to $-60,-100$ and -200 meshes. Using non-transgenic maize as the matrix, the pure maize lines (grain) MON810, Bt11, Bt176, T25, GA21, MON863, NK603, TC1507, ES3272, MON88017, MIR604 and MON87640 were added by the direct weighing method. The addition content of each standard analytical sample was as follows: $10^{-1} \sim 10^{-6}$ were added in each line (i.e. the mass ratio of $10 \% \sim 0.0001 \%$ ), where four lines of analytical samples (MON810, Bt11, Bt176 and T25) with the content of $10^{-1}$ were added. The $\mathrm{V}$ mixer was used to mix samples and to prevent cross contamination. Table 1 shows the typical addition content of the MON810 line.

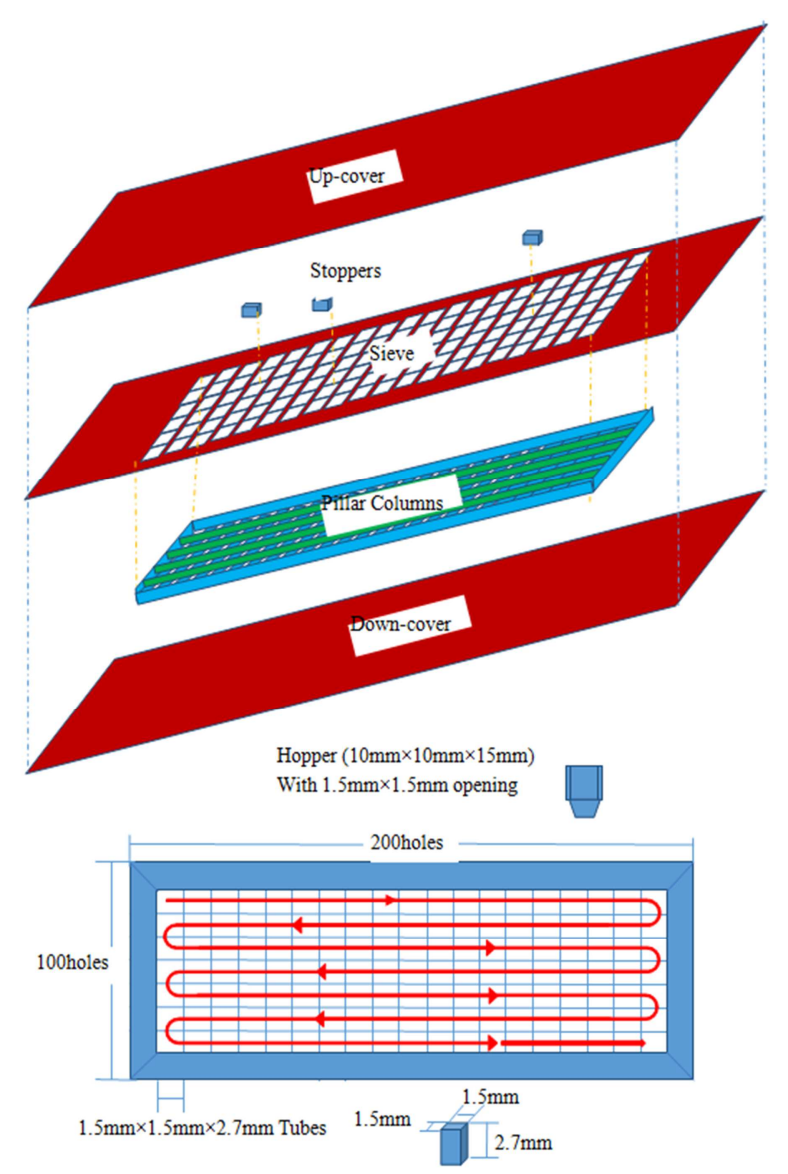

Figure 1. Structure ofsampling device.

Table 1. Typical Reference Analytical Sample.

\begin{tabular}{llllllll}
\hline \multirow{2}{*}{ Lines } & Addition content & $\mathbf{1 0}^{-\mathbf{1}}$ & $\mathbf{1 0}^{-2}$ & $\mathbf{1 0}^{-\mathbf{3}}$ & $\mathbf{1 0}^{-\mathbf{4}}$ & $\mathbf{1 0}^{-\mathbf{5}}$ & $\mathbf{1 0}^{-\mathbf{6}}$ \\
\cline { 2 - 7 } & Gross mass, $\mathbf{g}$ & $\mathbf{1 0 0}$ & $\mathbf{1 0 0}$ & $\mathbf{1 0 0}$ & $\mathbf{1 0 0}$ & $\mathbf{1 0 0}$ & $\mathbf{2 5 0}$ \\
\hline \multirow{3}{*}{ M1: maize, -60 mesh } & GMO(MON810) Mass, g & 10.134 & 1.012 & 0.0987 & 0.0122 & 0.00109 & 0.00011 \\
& Matrix mass, g & 90.389 & 99.221 & 99.856 & 99.925 & 100.721 & 100.454 \\
& Actual content, \% & 10.08 & 1.010 & 0.0987 & 0.0122 & 0.00108 & 0.00011 \\
& GMO(MON810) Mass, g & 10.295 & 1.366 & 0.1067 & 0.0091 & 0.00102 & 0.00012 \\
M2:maize, -100 mesh & Matrix mass, g & 91.478 & 99.254 & 99.528 & 99.473 & 100.695 & 100.268 \\
& Actual content, \% & 10.12 & 1.358 & 0.107 & 0.0091 & 0.00101 & 0.00012 \\
& GMO(MON810) Mass, g & 10.658 & 1.201 & 0.1066 & 0.0102 & 0.00117 & 0.0001 \\
M3:maize, -200 mesh & Matrix mass, g & 91.141 & 99.959 & 99.791 & 99.936 & 100.511 & 100.104 \\
& Actual content, \% & 10.47 & 1.187 & 0.107 & 0.0102 & 0.00116 & 0.00010 \\
\hline
\end{tabular}




\subsection{Test Portion Sampling Device}

A minitype sampling device was designed and manufactured; the structure is shown in Figure 1.

\subsection{Methods}

According to the charging method shown in Figure 1, the reference analytical sample was paved into the microtubes $(1.5 \mathrm{~mm} \times 1.5 \mathrm{~mm} \times 2.7 \mathrm{~mm})$, each micro tube contains about $5 \mathrm{mg}$ sample.

For each reference analytical sample, 10 duplicate sets of increments were taken by using systimatic sampling method. The mass and number of increments in each duplicate are listed here: $5 \mathrm{mg} \times 5,25 \mathrm{mg} \times 1,5 \mathrm{mg} \times 10,10 \mathrm{mg} \times 5,25 \mathrm{mg} \times 2$, $50 \mathrm{mg} \times 1,5 \mathrm{mg} \times 20,10 \mathrm{mg} \times 10,20 \mathrm{mg} \times 5,50 \mathrm{mg} \times 2,100 \mathrm{mg} \times 1$, $10 \mathrm{mg} \times 20,20 \mathrm{mg} \times 10,40 \mathrm{mg} \times 5,100 \mathrm{mg} \times 2,200 \mathrm{mg} \times 1$.
A $10 \mathrm{mg}$ test portion includes samples in two consecutive microtubes, and so on. Combine the selected increments to make up test portions: $25 \mathrm{mg} \times 20 ; 50 \mathrm{mg} \times 40 ; 100 \mathrm{mg} \times 50$; $200 \mathrm{mg} \times 50$.

\section{Results and Discussion}

\subsection{Testing Results}

GMO contents in the test portions were tested in a random order by the same DNA exaction kit and the same PCR, one result was obtained on one test portion. By comparing the RSDs of various sampling methods, it was found that the results of all strains were basically consistent. The data of MON810 were listed as a representative in table 2, 3 and 4.

Table 2. RSD of test portionsfrom the Reference Analytical Sample and by analysis-M1.

\begin{tabular}{|c|c|c|c|c|c|c|}
\hline \multicolumn{7}{|c|}{ M1: -60 mesh, $25 \mathrm{mg}$} \\
\hline Increments & $10^{-1}$ & $10^{-2}$ & $10^{-3}$ & $10^{-4}$ & $10^{-5}$ & $10^{-6}$ \\
\hline 5 & $18.3 \%$ & $19.4 \%$ & $20.9 \%$ & $65.8 \%$ & $416.8 \%$ & $931.6 \%$ \\
\hline 1 & $24.7 \%$ & $28.1 \%$ & $29.5 \%$ & $104.0 \%$ & $422.7 \%$ & $931.6 \%$ \\
\hline \multicolumn{7}{|c|}{ M1: -60 mesh, $50 \mathrm{mg}$} \\
\hline Increments & $10^{-1}$ & $10^{-2}$ & $10^{-3}$ & $10^{-4}$ & $10^{-5}$ & $10^{-6}$ \\
\hline 10 & $13.0 \%$ & $14.8 \%$ & $12.2 \%$ & $51.1 \%$ & $159.9 \%$ & $785.8 \%$ \\
\hline 5 & $16.7 \%$ & $18.6 \%$ & $17.6 \%$ & $62.7 \%$ & $393.5 \%$ & $931.6 \%$ \\
\hline 2 & $18.8 \%$ & $21.5 \%$ & $20.9 \%$ & $76.6 \%$ & $314.0 \%$ & overflow \\
\hline 1 & $19.8 \%$ & $19.7 \%$ & $18.6 \%$ & $77.4 \%$ & $262.3 \%$ & $852.7 \%$ \\
\hline \multicolumn{7}{|c|}{ M1: -60 mesh, $100 \mathrm{mg}$} \\
\hline Increments & $10^{-1}$ & $10^{-2}$ & $10^{-3}$ & $10^{-4}$ & $10^{-5}$ & $10^{-6}$ \\
\hline 20 & $10.2 \%$ & $11.9 \%$ & $9.6 \%$ & $35.0 \%$ & $149.4 \%$ & $598.2 \%$ \\
\hline 10 & $13.2 \%$ & $13.4 \%$ & $15.6 \%$ & $46.2 \%$ & $244.2 \%$ & $784.3 \%$ \\
\hline 5 & $13.3 \%$ & $12.1 \%$ & $14.4 \%$ & $47.5 \%$ & $164.8 \%$ & $794.9 \%$ \\
\hline 2 & $13.5 \%$ & $13.5 \%$ & $13.2 \%$ & $44.6 \%$ & $194.6 \%$ & $854.1 \%$ \\
\hline 1 & $13.7 \%$ & $15.6 \%$ & $15.1 \%$ & $50.2 \%$ & $317.7 \%$ & $931.6 \%$ \\
\hline \multicolumn{7}{|c|}{ M1: -60 mesh, $200 \mathrm{mg}$} \\
\hline Increments & $10^{-1}$ & $10^{-2}$ & $10^{-3}$ & $10^{-4}$ & $10^{-5}$ & $10^{-6}$ \\
\hline 20 & $8.9 \%$ & $8.2 \%$ & $8.1 \%$ & $31.1 \%$ & $127.0 \%$ & $574.4 \%$ \\
\hline 10 & $10.3 \%$ & $9.1 \%$ & $7.8 \%$ & $26.7 \%$ & $125.2 \%$ & $637.0 \%$ \\
\hline 5 & $10.3 \%$ & $10.2 \%$ & $10.4 \%$ & $33.8 \%$ & $137.7 \%$ & $575.6 \%$ \\
\hline 2 & $8.8 \%$ & $9.8 \%$ & $10.0 \%$ & $36.4 \%$ & $151.9 \%$ & $779.3 \%$ \\
\hline 1 & $10.1 \%$ & $10.0 \%$ & $9.2 \%$ & $37.0 \%$ & $144.1 \%$ & $794.9 \%$ \\
\hline
\end{tabular}

Table 3. RSD of test portions from Reference Analytical Sample and by analysis-M2.

\begin{tabular}{|c|c|c|c|c|c|c|}
\hline \multicolumn{7}{|c|}{ M2: -100 mesh, $25 \mathrm{mg}$} \\
\hline Increments & $10^{-1}$ & $10^{-2}$ & $10^{-3}$ & $10^{-4}$ & $10^{-5}$ & $10^{-6}$ \\
\hline 5 & $21.4 \%$ & $19.7 \%$ & $20.7 \%$ & $27.3 \%$ & $129.2 \%$ & $784.3 \%$ \\
\hline 1 & $24.7 \%$ & $27.4 \%$ & $27.4 \%$ & $39.8 \%$ & $185.0 \%$ & $570.1 \%$ \\
\hline \multicolumn{7}{|c|}{ M2: -100 mesh, $50 \mathrm{mg}$} \\
\hline Increments & $10^{-1}$ & $10^{-2}$ & $10^{-3}$ & $10^{-4}$ & $10^{-5}$ & $10^{-6}$ \\
\hline 10 & $13.3 \%$ & $14.6 \%$ & $13.6 \%$ & $21.0 \%$ & $85.2 \%$ & $413.7 \%$ \\
\hline 5 & $14.2 \%$ & $17.9 \%$ & $16.1 \%$ & $24.2 \%$ & $122.9 \%$ & $476.5 \%$ \\
\hline 2 & $16.3 \%$ & $19.9 \%$ & $19.4 \%$ & $25.0 \%$ & $101.3 \%$ & $726.5 \%$ \\
\hline 1 & $19.1 \%$ & $19.1 \%$ & $20.4 \%$ & $30.0 \%$ & $139.9 \%$ & $716.0 \%$ \\
\hline \multicolumn{7}{|c|}{ M2: -100 mesh, $100 \mathrm{mg}$} \\
\hline Increments & $10^{-1}$ & $10^{-2}$ & $10^{-3}$ & $10^{-4}$ & $10^{-5}$ & $10^{-6}$ \\
\hline 20 & $10.9 \%$ & $8.7 \%$ & $11.1 \%$ & $16.9 \%$ & $56.5 \%$ & $206.3 \%$ \\
\hline 10 & $15.2 \%$ & $12.9 \%$ & $12.7 \%$ & $17.6 \%$ & $78.4 \%$ & $243.5 \%$ \\
\hline 5 & $13.4 \%$ & $13.0 \%$ & $13.0 \%$ & $18.7 \%$ & $75.5 \%$ & $477.3 \%$ \\
\hline 2 & $14.6 \%$ & $13.5 \%$ & $13.8 \%$ & $18.7 \%$ & $90.7 \%$ & $407.4 \%$ \\
\hline 1 & $13.2 \%$ & $13.6 \%$ & $13.9 \%$ & $16.5 \%$ & $87.2 \%$ & $398.5 \%$ \\
\hline \multicolumn{7}{|c|}{ M2: -100 mesh, $200 \mathrm{mg}$} \\
\hline Increments & $10^{-1}$ & $10^{-2}$ & $10^{-3}$ & $10^{-4}$ & $10^{-5}$ & $10^{-6}$ \\
\hline
\end{tabular}




\begin{tabular}{llllll}
\hline 20 & $7.2 \%$ & $9.1 \%$ & $9.6 \%$ & $12.8 \%$ & $49.8 \%$ \\
10 & $9.7 \%$ & $9.8 \%$ & $9.4 \%$ & $14.7 \%$ & $59.2 \%$ \\
5 & $9.5 \%$ & $7.8 \%$ & $10.7 \%$ & $13.6 \%$ & $59 \%$ \\
2 & $9.5 \%$ & $8.6 \%$ & $11.3 \%$ & $14.9 \%$ & $5 \%$ \\
1 & $9.3 \%$ & $9.5 \%$ & $10.1 \%$ & $13.5 \%$ & $69.3 \%$ \\
\hline
\end{tabular}

Table 4. RSD of test portions from Reference Analytical Sample and by analysis-M3.

\begin{tabular}{|c|c|c|c|c|c|c|}
\hline \multicolumn{7}{|c|}{ M3: -200 mesh, $25 \mathrm{mg}$} \\
\hline Increments & $10^{-1}$ & $10^{-2}$ & $10^{-3}$ & $10^{-4}$ & $10^{-5}$ & $10^{-6}$ \\
\hline 5 & $19.8 \%$ & $18.5 \%$ & $21.4 \%$ & $21.6 \%$ & $41.1 \%$ & $204.6 \%$ \\
\hline 1 & $23.3 \%$ & $27.8 \%$ & $31.2 \%$ & $29.8 \%$ & $54.3 \%$ & $444.8 \%$ \\
\hline \multicolumn{7}{|c|}{ M3: -200 mesh, $50 \mathrm{mg}$} \\
\hline Increments & $10^{-1}$ & $10^{-2}$ & $10^{-3}$ & $10^{-4}$ & $10^{-5}$ & $10^{-6}$ \\
\hline 10 & $16.3 \%$ & $14.8 \%$ & $15.1 \%$ & $14.5 \%$ & $30.8 \%$ & $153.1 \%$ \\
\hline 5 & $18.0 \%$ & $17.7 \%$ & $17.2 \%$ & $16.8 \%$ & $29.7 \%$ & $190.4 \%$ \\
\hline 2 & $20.5 \%$ & $17.9 \%$ & $17.9 \%$ & $17.6 \%$ & $42.3 \%$ & $279.8 \%$ \\
\hline 1 & $17.3 \%$ & $20.0 \%$ & $16.4 \%$ & $23.3 \%$ & $35.1 \%$ & $373.1 \%$ \\
\hline \multicolumn{7}{|c|}{ M3: -200 mesh, $100 \mathrm{mg}$} \\
\hline Increments & $10^{-1}$ & $10^{-2}$ & $10^{-3}$ & $10^{-4}$ & $10^{-5}$ & $10^{-6}$ \\
\hline 20 & $9.9 \%$ & $9.1 \%$ & $10.8 \%$ & $10.0 \%$ & $18.7 \%$ & $120.5 \%$ \\
\hline 10 & $13.0 \%$ & $13.3 \%$ & $13.1 \%$ & $13.3 \%$ & $27.3 \%$ & $119.1 \%$ \\
\hline 5 & $11.4 \%$ & $13.1 \%$ & $12.8 \%$ & $15.0 \%$ & $23.7 \%$ & $177.8 \%$ \\
\hline 2 & $13.0 \%$ & $12.1 \%$ & $13.2 \%$ & $13.9 \%$ & $23.4 \%$ & $132.0 \%$ \\
\hline 1 & $15.4 \%$ & $17.5 \%$ & $14.0 \%$ & $13.3 \%$ & $26.2 \%$ & $112.6 \%$ \\
\hline \multicolumn{7}{|c|}{ M3: -200 mesh, $200 \mathrm{mg}$} \\
\hline Increments & $10^{-1}$ & $10^{-2}$ & $10^{-3}$ & $10^{-4}$ & $10^{-5}$ & $10^{-6}$ \\
\hline 20 & $8.2 \%$ & $8.6 \%$ & $9.4 \%$ & $9.6 \%$ & $16.7 \%$ & $93.9 \%$ \\
\hline 10 & $9.9 \%$ & $8.8 \%$ & $9.2 \%$ & $9.4 \%$ & $18.1 \%$ & $103.2 \%$ \\
\hline 5 & $9.4 \%$ & $9.6 \%$ & $8.7 \%$ & $10.8 \%$ & $16.3 \%$ & $119.4 \%$ \\
\hline 2 & $8.9 \%$ & $8.7 \%$ & $10.3 \%$ & $10.3 \%$ & $18.6 \%$ & $101.0 \%$ \\
\hline 1 & $9.3 \%$ & $9.5 \%$ & $10.3 \%$ & $10.6 \%$ & $18.8 \%$ & $106.6 \%$ \\
\hline
\end{tabular}

\subsection{Analysis and Optimization of Parameters}

\subsubsection{Parameters Affecting RSD}

According to Table 2-4, the main parameters influencing the RSD of analytical samples included the content $a_{A S}$ (AS, Analytical Sample), particle size $d_{A S}$, test portion mass $M_{T P}$ (TP, Test Portion), the number of increments $n_{I T}$ (IT, Increase composition of Test Portion).

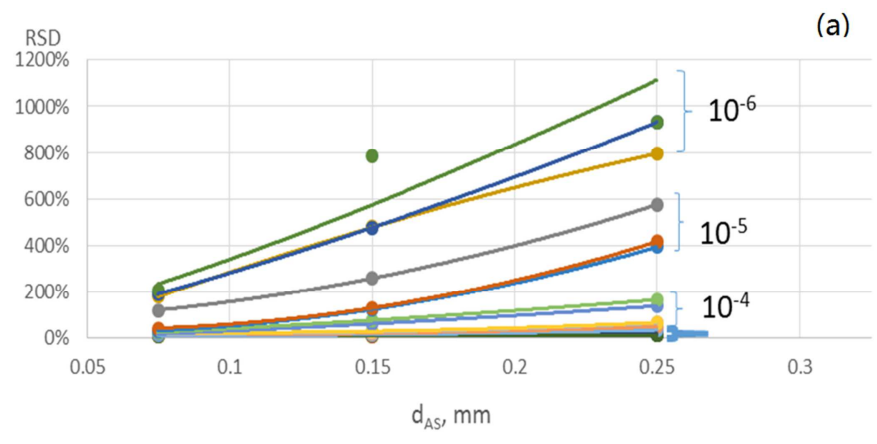

\subsubsection{Optimization on Particle Size of Analytical Samples}

The nominal (particle size) of analytical sample is of great concern to RSD, as shown in Table 2-4. The overall trend is that smaller particle size leads to smaller RSD. On the higher level $\left(10^{-1} \sim 10^{-3}\right)$, particle size has little effect on RSD, this may be explained by increasing aggregated distribution; on the lower level $\left(10^{-4} \sim 10^{-6}\right)$, the effect of particle size to RSD increase with the content level going down (see Figure 2).

RSD

(b)

(a) RSD between $0 \%$ and $1200 \%$, (b) Enlarge the RSD part of (a) between $0 \%$ and $25 \%$.

Figure 2. Effect of particle size of analytical sample on RSD.

Theoretically, solid sample could be crushed to a very fine size (e.g. -10000mesh), however in practice, crushing the laboratory sample unboundedly will waste time and money, even impossible and unnecessary. For agricultural product with high oil content, it is impossible to be crushed to -200 mesh, because in this case the product has become thick or their property has been changed due to high temperature. For the products studied, it is feasible to crush them to -100 mesh. Forthe routine sampling and analysis, the analytical sample is suggested to be crushed to -100 mesh or lower.

For high content analytical samples $\left(10^{-1} \sim 10^{-3}\right)$, there is no 
significant difference on RSD between -100mesh and -200mesh samples, when the mass of test portion is over $100 \mathrm{mg}$, they are also almost the same for low content $\left(10^{-4}\right)$, however, the RSD difference will be 4 5 times for low content samples $\left(10^{-5} \sim 10^{-6}\right)$. That's to say, for the analytical samples with over $10^{-4}$ content, reducing particle size is unnecessary, only when the content is lower than $10^{-4}$, it is economical for reducing the particle size. On the other hand, RSD could also be reduced by increasing the mass of test portion or the number of increments, reducing particle size is not always the best and necessary option.

In order to keep the consistency with routine analytical conditions, the particle size of the analytical sample is fixed to -100 mesh hereafter. On the study stage, some analytical samples were crushed to -200 mesh after lyophilization to prevent over estimation of the total analytical variance.

\subsubsection{Minimum Mass of Test Portion}

The effect on total analytical RSD by different mass of test portion is shown in Figure 3. In the range given in current analytical methods $(25 \sim 300 \mathrm{mg})$, RSD tends to be lower down with increasing mass of test portion. When it is over $100 \mathrm{mg}$, the falling rage becomes narrow. RSDs for $100 \mathrm{mg}$ and $200 \mathrm{mg}$ test portions only differ 1.5 times, and those for $50 \mathrm{mg}$ and $100 \mathrm{mg}$ differ 2.3 times. Analysing the trend of data, the reasonable mass is $200 \mathrm{mg}$.
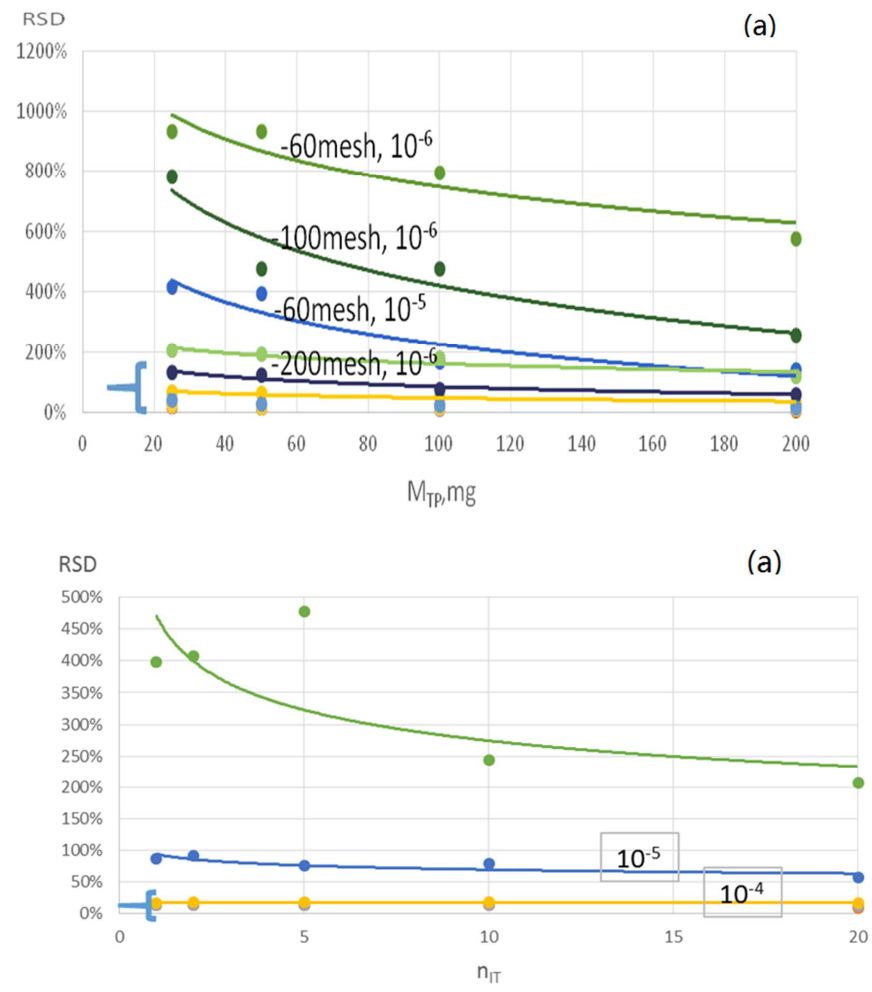

(a) RSD between $0 \%$ and $500 \%$, (b) Enlarge the RSD part of (a) between $0 \%$ and $30 \%$.

Figure 4. Influence of the number of increments on RSD.

\subsection{Analysis of RSD Derived from Various Approaches of Sampling and Testing}

The total analytical RSDs of the results from the analytical
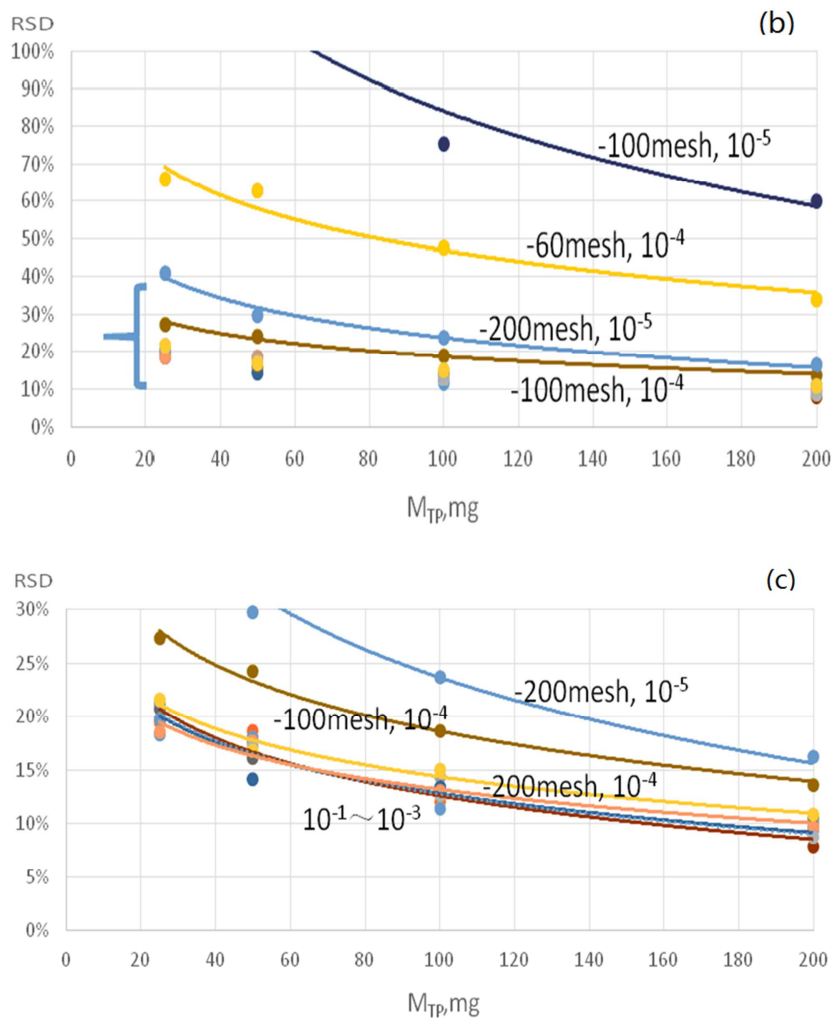

Figure 3. Trends of RSD against mass of test portion.

(a) RSD between $0 \%$ and $1200 \%$, (b) Enlarge the RSD part of (a) between $0 \%$ and $100 \%$, (c) Enlarge the RSD part of (b) between $0 \%$ and $30 \%$.

\subsubsection{Number of Increments Composing of Test Portion}

For $-100 \mathrm{mesh} 100 \mathrm{mg}$ test portion, plot RSD against $n_{I T}$ in Figure 4. It shows that the effect of $n_{I T}$ on RSD is obvious only when the content is very low $\left(10^{-5} \sim 10^{-6}\right)$. More increments $\left(n_{I T} \geq 5\right)$ are recommended to be taken to make up a test portion, because this operation is very easy, taking test portion one-off should be avoided, so that the distribution variance of the analytical sample could be reduced as far as possible.

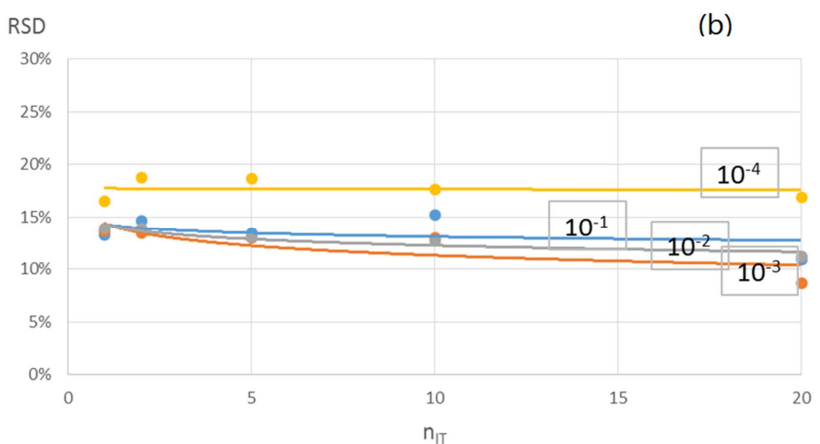

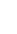

samples by different sampling and assay approached were evaluated and listed in Table 5, where the particle sizes were $-100 \mathrm{mesh}$ and $-200 \mathrm{mesh}$, the masses of test portions were 50 to $200 \mathrm{mg}$, 5 increments were taken to make up a test portion, 
single extraction of DNA and single PCR analysis for each of 1 to 3 duplicate test portions were carried out to obtained GMO contents.

In Table 5, in the range of high content $\left(10^{-1} \sim 10^{-3}\right)$, in order to control the total analytical RSD less than $10 \%$, two duplicate test portion with the mass more than $100 \mathrm{mg}$ and particle size lower than -100 mesh should be analyzed; if the control limit is $14.1 \%$, the mass of each test portion could be reduced to $50 \mathrm{mg}$. In routine procedure, analyzing two duplicates on -100 mesh $100 \mathrm{mg}$ test portions is feasible; it means the RSD could be controlled lower than $10 \%$. In the range of medium content (about $10^{-4}$ ), RSD could be limited lower than $14.1 \%$, by usingtwo-200mesh, $100 \mathrm{mg}$ duplicate test portions; in the range of low content (about $10^{-5}$ ), the RSD is hardly to be controlled to be lower than $20 \%$ when $-100 \mathrm{mesh} 200 \mathrm{mg}$ test portions were used, but if three -200 mesh $100 \mathrm{mg}$ test portions were used; in the very low content $\left(10^{-6}\right.$ or lower), even -200 mesh analytical sample were used, the RSD can be hardly controlled less than $50 \%$, for three duplicate, the RSD is still larger than $70 \%$.

Table 5. RSDs by Different Approaches.

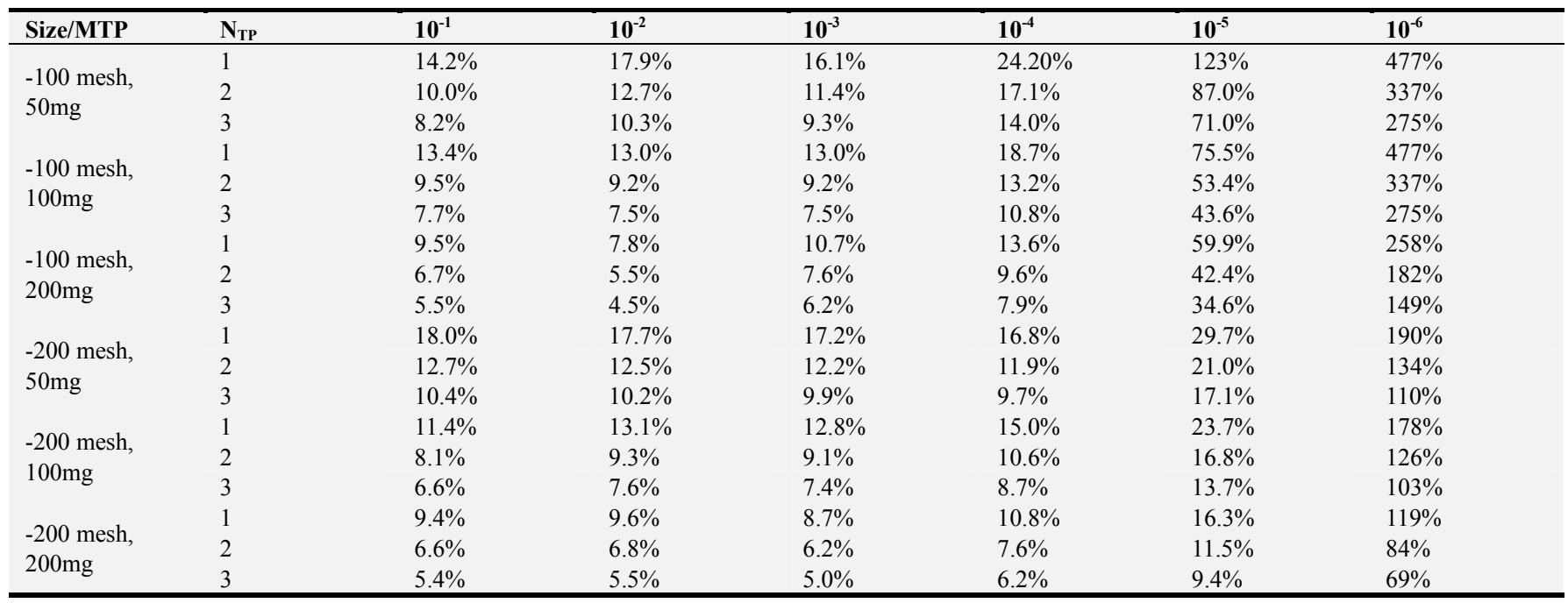

Because the commonly used PCR reaction systems require DNA concentration $50 \sim 100 \mathrm{ng} / \mathrm{iL}$ and the volume of DNA extraction solution $25 \sim 100 \mathrm{iL}$, that is, DNA mass in the solution is $1 \sim 10 \mathrm{mg}, 50 \mathrm{mg}$ test portion is suitable for about $10^{-2} \mathrm{GMO}$ content; $100 \mathrm{mg}$ and $200 \mathrm{mg}$ are suitable for about $10^{-3}$; and when $10^{-4}$ content level is tested, more test portion or further concentrating of DNA extraction solution should be used, so that the concentration of DNA could fall in $50 \sim 100 \mathrm{ng} / \mathrm{iL}$ (while the quantitative limit is $1 \mathrm{ng} / \mathrm{iL}$, equivalent to 100 copies in $2 \mathrm{iL}$ ). In practice, using 10iL DNA extraction solution, the concentration of the solution extracted from $100 \mathrm{mg}$ test portion with $10^{-4}$ content is about $1 \mathrm{ng} / \mathrm{iL}$, and for $10^{-5}$, the mass of test portion needs to be $1 \mathrm{~g}$, and for $10^{-6}, 10 \mathrm{~g}$. This is the reason why the total analytical
RSD could not be reduced for low and very low content samples.

$50 \sim 300 \mathrm{mg}$ test portion is used by current DNA extraction kits, according to above discussion, the kits with this range of mass could only be used for the samples which GMO content higher than $10^{-4}$. Therefore, based on current level of PCR test, the limit in regulation should not be set lower than $10^{-4}$. Due to the same consideration, in this project, we will focus on those with GMO content higher than $10^{-5}$, and the limit of $\mathrm{RSD}(\mathrm{TP})$ is set on $10 \%$. The very low content sample $\left(\sim 10^{-6}\right)$ will not be studied.

According to the above discussion, recommended approaches for taking test portions from the analytical sample and expected RSD are listed in Table 6.

Table 6. Recommended sampling approaches for routine analysis.

\begin{tabular}{lllll}
\hline Controlled RSD & Content $\boldsymbol{a}_{A S}$ & Particle Size & $\boldsymbol{M}_{T P}, \mathbf{m g}$ & $\boldsymbol{n}_{T P}$ \\
\hline$\sim 10 \%$ & $\geq 0.1 \%$ & $-100 \mathrm{mesh}$ & 100 & 2 \\
$\%$ & $\geq 0.01 \%$ & $-100 \mathrm{mesh}$ & 100 & 3 \\
\hline
\end{tabular}

\section{Conclusions}

The relative sampling RSD (TP) mainly depends on the particle size of the analytical sample and the mass test portion, i.e. the inherent heterogeneity of the analytical sample plays a key role. The number of increments constituted the test portion affect RSD (TP) to some extent. The main approaches for reducing the total analytical RSD (TAE) are reducing particle size of analytical sample, increasing mass of test portion and increasing duplicate number.

In practice, based on current laboratory testing conditions and current used kits, for high content analytical sample $(>0.01 \%)$, it is necessary to use more than 2 duplicate test portions with at least -100 mesh particle size and $200 \mathrm{mg}$ mass. With the current analytical techniques, it is meaningless to study or analyze very low content samples (such as $10^{-6}$ ).

For the analytical sample which is fit for the purpose of 
analysis, the number of increments constituting the test portion has week effect on RSD(TAE), however, taking test portion one-off from the analytical sample is not recommended, the number prefers to be about 5 .

The conclusions in this article are based on the content, particle size of analytical sample, the number of increments constituting test portion and mass of test portion. These factors are independent on species or strains of the product, so the conclusions are suitable to all species and strains, provided that the solid particles could be crushed to required particle size.

\section{Acknowledgements}

This work is supported by the National science and technology major project of China (No. 2018ZX08012-001).

\section{References}

[1] Http://www.isaaa.org, (cited 2015-08-20), ISAAA Brief 49-2014: "A record 181.5 million hectares of biotech crops were grown globally in 2014, at an annual growth rate of between 3 and $4 \%$, up 6.3 million hectares from 175.2 million hectares in 2013. This year, 2014, was the 19th year of commercialization, 1996-2014, when growth continued after a remarkable 18 consecutive years of increases every single year; notably 12 of the 18 years were double-digit growth rates."

[2] Y. Sheng, W. T. Xu, and Y. B. Luo, "Commercialization of enetically modified organisms," J. Agric Biotech, vol. 12, pp. 1479-1487, 2013.

[3] P. L. Liu, N. Li, and Y. L. Zhou, "Safety administration system for transgenic organism in America and its enligh tenement for China," J. Agric Sci Tech, vol.5, pp.49-53, 2009.

[4] C. James, "The 2014 global biotech/gm crops commercialization development situation," China Biotech, vol.1, pp.1-14, 2015.

[5] E. Barbau-Piednoir, P. Stragier, N.Roosens et.al, "Inter-laboratory testing of GMO detection by combinatory SYBR ${ }^{\circledR}$ green PCR screening(Co SYPS)," Food Anal Methods, vol.8, pp. 1719-1728, 2014.

[6] T. Twardowski and A. Malyska, "Uninformed and disinformed society and the GMO market," Trends Biotechnol, vol.1, pp. $1-3,2015$.

[7] Y. M. Han, G. Q. Zhai, and J. F. Xu, "The evolution of the eu regulation system of transgenic organisms and the enlightenment to our country," J. Zhejiang Agric Sci, vol.11, pp. 1482-1485, 2013.

[8] K. R. Emslie, L. Whaites, K. R. Griffiths et al, "Sampling plan and test protocol for the semiquantitative detection of genetically modified canola (Brassica napus) seed in bulk canola seed," J. Agric Food Chem, vol.11, pp.4414-4421, 2007.

[9] S. Kay and C. Paoletti, "Sampling Strategies for GMO detection andor Quantification," EC Directorate General JRC, 2001.

[10] ISO 542:1990, Oilseeds-Sampling.

[11] ISO 13690:1999, Cereals, pulses and milled products-Sampling of static batches.

[12] S. Kay and V. D. E. Guy, "The limit of GMO detection," Nature Biotech, vol.19, pp. 405-409, 2001.

[13] ISO 24333:2009, Cereals and cereal products-Sampling.

[14] ISO DTR29263, Cereals and cereal products-Sampling studies.

[15] GB/T 19495.7-2004, Detection of genetically modified organisms and derived products-Methods for sampling preparation.

[16] J. Gilbert, "Sampling of raw materials and processed foods for the presence of GMOs," Food Control, vol. 10, pp. 363-365, 1999.

[17] G. S. Begg, D. W.Cullen, P. P. M. Iannetta, "Sources of uncertainty in the quantification of genetically modified oilseed rape contamination in seed lots," Transgenic Research, vol. 16, No. 1, pp. 51-63, 2007.

[18] C. Brera, E. Donnarumma, R. Onori, "Evaluation of sampling criteria for the detection of gm soybeans in bulk," Italian Journal of Food Science, vol. 17, No. 2, pp. 177-185, 2005.

[19] K. R. Emslie, L. Whaites, K. R. Griffiths, "Sampling plan and test protocol for the semiquantitative detection of genetically modified canola (Brassica napus) seed in bulk canola seed," $\mathrm{J}$ of Agricultural and Food Chemistry, vol, 55, No. 11, pp. 4414-4421, 2007.

[20] P. Minkkinen, K. H. Esbensen, and C. Paoletti, "Representative sampling of large kernel lots II. Application to soybean sampling for GMO control," Trends in Analytical Chemistry, vol. 32, pp. 165-177, 2012.

[21] R. Onori, R. Lopardo, M. D. Giacomo, B. D. Santis, E. Prantera, E. Palmaccio, C. Brera, "Traceability of genetically modified Roundup Ready soybean: A case study on sampling and analytical uncertainty along processing chain," Food Control, vol. 34, pp. 494-501, 2013.

[22] K. Yamamura, J. Mano, and H. Shibaike, "Optimal definition of the limit of detection (LOD) in detecting genetically modified grains from heterogeneous grain lots," Quality Technology and Quantitative Management, vol. 16, No. 1, pp. 36-53, 2019. 